\title{
Humanized Design and Its Application in Modern products
}

\author{
Wei CHEN \\ The city vocational college of Jiangsu, Nanjing, China \\ chenwei@jstvu.edu.cn
}

Keywords: modern products; humanized design

\begin{abstract}
Paying great attention humanized design, is precisely lofty ideal which the moder products pursues, namely produces humanization design product for the humanity, accomplishes a more comfortable life and the working conditions. From five aspects of the physical level's concern, the physiological level's concern, the psychological level's concern, and the social level's concern shows the application of humanized design in modern products.
\end{abstract}

\section{Introduction}

Modern product design should attach importance to engineering design, more attach important is to people-centered design. By design activities, to improve the quality of human life and quality of work, to design the human way of life.

Humanized design is to emphasize the design thought, the human factor in the first place.

With the progress of science and technology, the development of the society and the general improvement of people's living standard, people not only meet the requirement of product's use function, and humanized design of products is becoming more and more demanding. From the development trend of modern product, humanized design is more and more attention.

\section{Humanized design}

\subsection{Meaning of humanized design}

Humanized design is to design products to meet of the people's physiological and psychological needs, material and spiritual needs, make the people obtain the feeling of harmony, comfort and satisfaction in use or operation

Paying attention to humanized design is lofty ideals in moredn product design. That is to say, the human produces more personalized products, create more comfortable living and working environment.

\subsection{Considering factors in humanized design}

In modern product design, there are many considering factors, but from the perspective of the humanized design needs, people need consider two main factors - human feeling and human emotion.

1) In the feeling of people: The feelling of people's vision, hearing, touch ect. can best embody the humanized design. This is because the most striking $\mathrm{f}$ eatures of humanized design are to meet the people's various sensory experience. That is, the consumers feel the physical and mental pleasure and are full of vitality after they obtain practical, economic, beautiful products.

In modern product design, therefore, in order to satisfy people's all sorts of feeling, feelling design must be to consider - consider eye-catching visual, consider the auditory attention, consider the comfortable sense of touch, etc.

2) In the human emotion: The development of science and technology and material wealth are not proportional growth with human emotion, on the contrary, people's feelings are more and more indifference.

The development of computer technology has brought the popularity of computer, to gradually 
realize the intelligent residential, office automation. Especially the rapid development of Internet, people can work at home, shop at home, chat with friends at home. Even fry stock, deposit, pay various fees, etc. at home. So, direct communication is less, real communication between them is also less, human emotion is more and more frustrated. This emotional imbalance will inevitably lead to some social crisis - neighbors help less, less people ready to help others,... .

In product design, therefore, in order to recover and balance people's emotion, emotional design with human must become modern product design another factor to consider - consider the interpersonal communication, consider the communication of human and the nature consider the ecological balance, etc.

\section{Humanized design and its application in modern products}

\section{1 Ideas of humanized design}

In the 1980s and 1990s, especially in the 21st century, the humanized design of modern products received great attention. Based on the person's feeling and emotion factors, the designers put forward the idea of humanized design, that is created to adapt to the human body all sorts of feelings and the human emotions, and on the back of the products could let a person get more care.

These cares include the care of physical level, the care of physiological level, the care of psychological level, the care of the crowd subdivision and the care of social level.

These cares embodies t fully he humanized design factors.

\section{2 Humanized design and its application in modern products}

1) the care of physical leve

In the care of physical leve, the humanized design of modern products is based on the scientific design, the function of the product and the structure of the product. This is physical leve.If there is no it, product design itself is meaningless.

The invention of the remote controls is to embody a humanized design from the aspects of physical level. The purpose inventing remote controls is for the convenience of people's lives, is a kind of save labour tools. The function of the remote controls is conveniently, easily manipulate the controlled objects within a certain distance, through its keys.

When people holding TV remote controls sit on the sofa or lie on the bed, they easy to convert the TV channels, to choose themselves favorite program.

When car drivers holding remote control car keys close to or just leave their cars, they can easily open or shut car's doors.

When there are air conditioning remote controls, people can easily change indoor temperature.

Figure 1 is TV remote controls, remote control car key, air conditioning remote controls.
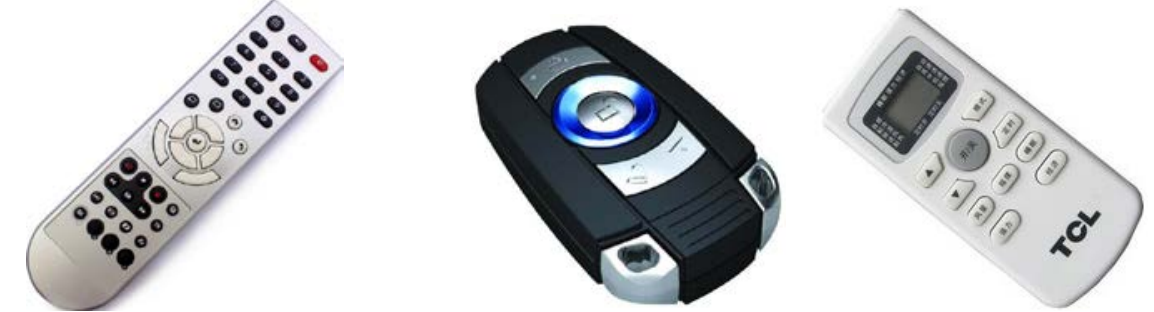

Fig. 1 TV remote controls, remote control car key, air conditioning remote controls.

Most button arrangement of remote controls is to make the entire control panel in the clear. In these buttons, some are words, some are symbols/diagram, they distribute around the fuselage harmonically. These words, symbols/diagram are simple, easy to understand.The people easily operate them. The humanized design make you know at a glance their function, and don't have to guess what's the matter.

Humanized design of modern products not only brings our life to convenience, more important is to make the product more harmonious relationship between users and products. 
2) the care of physiological level

In the care of physiological leve, ergonomics is the basis of realizing the humanized design of modern product. Products humanized design should comply with ergonomics, truly reflects the respect for the people and cares about them.

To apply ergonomics to product interface design is in essence to meet people's physiological needs, namely the care of physiological level.

The design of mobile phone interface should fully embody the people feeling. The feeling include visual interface, auditory interface and touch interface.

According to habit of people hand movements, visual screen, auditory, the phone screen is designed to the horizontal form or vertical form. Vertical screen can ensure people easily carrying, operating and answering at ordinary times. Horizontal screen can guarantee people comfortably watching the film and television programme, playing the game, as shown in figure 2 and figure 3.

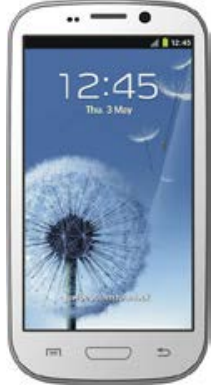

Fig.2 mobile phone of vertical screen

3) the care of psychological level

If the design of modern products only pursues their functions and structures to want to in order to humanization, this is not feasible. It will deviate from the humanization.This requests us in the focus on the care of physical level, the physiological level at the same time, also want to care about the person's psychology, and their emotion.

The satisfaction of psychological level is not as intuitive as the satisfaction of physical level, it is often ill-defined and unable to observe, even many users are unable to explain why they would like a product. This is the psychological reaction.

The product itself is no feelings. Once establishing some kind of emotional connection with people, there is life.

The life of the product is given by the human. When originally no life products are adored to the limit, they become a fetish. Fetish phenomenon is thought to be irrational and mental compulsion. It is linked with human emotions.

In the care of psychological level, the humanized design of the product give it life and emotion to make the person feel deep regreat at parting from it, and make the person feel happy in the process of using.

The nature of children is active. They like small animals. In order to make the children develop good personal habits and establish feelings with a toothbrush since the childhood, the toothbrush rack series of children's favorite have been designed. There are bee toothbrush rack, lady beetle toothbrush rack, zodiac toothbrush rack and mouse toothbrush rack etc. Figure 4 is a bee toothbrush rack. Figure 5 is alady beetle toothbrush rack..

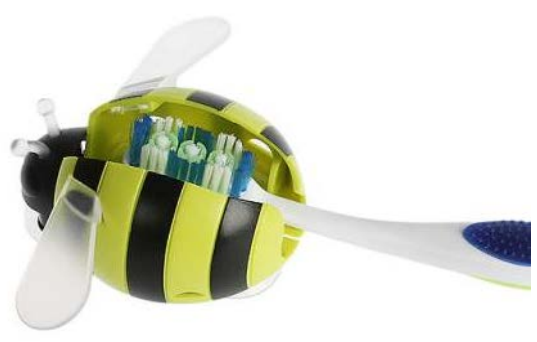

Fig. 4 a bee toothbrush rack

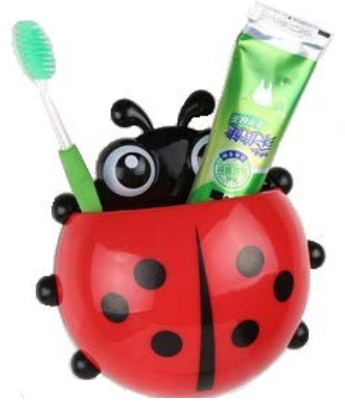

Fig.5 a lady beetle toothbrush rack 


\section{4) the care of the crowd subdivision}

In social big family, due to the laws of nature, everyone will experience from children, young, middle-aged to old age. Due to various reasons, some people healthfully live for a lifetime, and some people later disability. In addition, there are the gender differences and women during pregnancy etc. The children, pregnant women, the old man and people with disabilities etc. are classified as the vulnerable people groups. For them, the product design reflect more humanity care make everyone really enjoy equal rights.

The freedom of the vulnerable people groups is limited because of their physiological and psychological characteristics and the lack of the whole social environment system for their consideration. For a long time, when people design and develop products, they consider more young and healthy people, and consider less vulnerable groups.

Humanized design of products is as much as possible to remove barriers due to the inconvenience caused by the body, to make everyone have a happy enjoy using the product. From the crowd subdivision, humanized design is the common design.

The design of inclined type platen washing machine fully reflects the care of the crowd subdivision.

Throughout the washing machine market, no matter a pulsator washing machine, a agitator washing machine, or a drum washing machine, their appearance are basically the cube, which edges and corners are generally circular arc transition, to appear beautiful, generous.

In terms of the man-machine scale, the height of the washing machine is generally designed according to normal adults.

There are two types of the design of the door. One is at the upper, Another is at the front. For the former, when people take clothes, they will bend over, and easily tired. For the latter, they will squat, and also easily tired. For the elderly, the disabled, children, pregnant women, etc., they are more difficult in the operation of the washing machine, even unable to operate it.

How to solve these problems? Japan's Panasonic electric company used the common concept to design a new type of washing machine, that is NA - V80GD which is oblique type platen washing machine. As shown in figure 6.

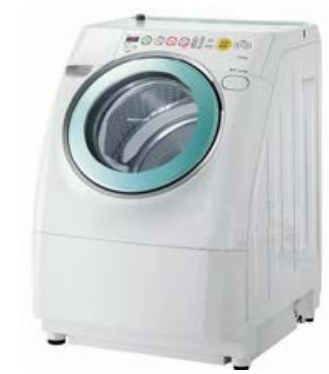

Fig. 6 NA-V80GD

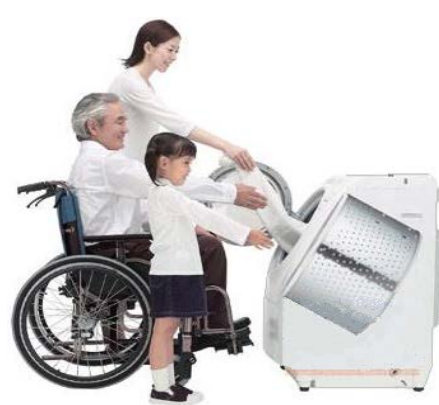

Fig.7 Everyone using the washing machine

The core of the design concept is to that different age, height, gender and special groups (including the disabled) can be convenient to use electrical appliances.

The front opening door creatively was designed at $30^{\circ}$ for NA - V80GD which is oblique type platen washing machine. So under any circumstances, anyone can be equal, safe and convenient to use the washing machine.

Tilt the door can make tall people don't have to squat beside the washing machine to take out or put in clothes. The short people and disabled persons sit on wheelchair also can easily take out, put in clothes. For pregnant women and children, they need to bend down gently to do it. As shown in figure 7. This design is very humanized design.

In addition, as the entrance is larger, the users can easily observe washing conditions inside the washing machine. At the same time, as they can see at the bottom of the barrel, the clothes won't be 
left out in the barrel. after washing.

5)the care of social level.

The care of social level of humanized design is for the care of people living environment.

The progress of science and technology promote the rapid growth of economy, the prosperity of the society, but it caused the environmental pollution.

No pollution or minimum contamination is humanized design considering problem This is the product green design. Green design is the humanized design which can embody the social level.Its essence is to make the product comee from nature and return to nature.

The flatware "Mater-Bi" which uses the mixture of starch and cellulose additives can be natural degradation and dissolved. It can be broken down in a short time.the $90 \%$ weight is broken down in 40 days. It is very green. Fig.8 is a biodegradable tableware.

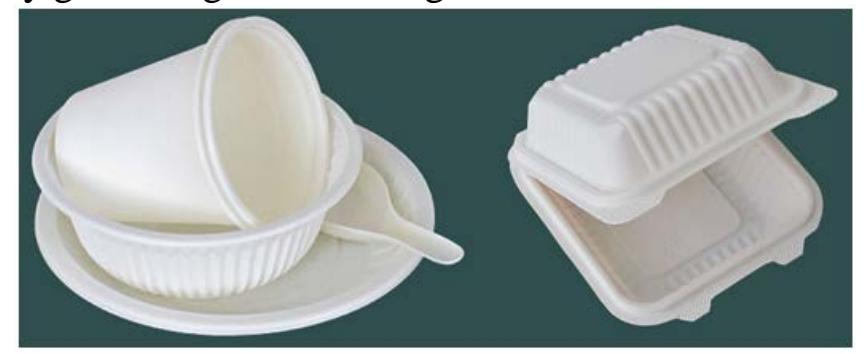

Fig.8 is a biodegradable tableware

\section{Summary}

Design is a creative activity, which achieves a certain purpose. It is the most basic activities of human survival and development.

The product design aims are meet the needs of people, so the product design must be a humanized design.

\section{Acknowledgments}

This research was supported by project on science and technology innovation team about application of the internet of things technology.

\section{Reference}

[1] Xiao-you He andYun-feng Xie: Humanized design. The first published by jiangsu arts publishing house,2001

[2] Cheng-qi Xue and Wei Chen: Industrial design basis. The second published by southeast university press, 2004

[3] Yu-liang Yu and Zhen-bang Chen: Product design and implementation-industrial design instance analysis [M]. The first published by mechanical industry publishing house, 2008

[4] Wei Chen: The common design and its application in industrial design. Journal of Development \& Innovation of Machinery \& Electrical Products Vol. 22(2)(2009), p.74 76

[5] Li Ke and Wei-she Zhang.:Analysis of Design of Human Nature in Modern Products. Journal of Development \& Innovation of Machinery \& Electrical Products Vol. 17(5)(2004), p.20 22

[6] Anonymity: Photo of mobile phone, tooth brush holder, tableware etc.[EB/OL]. The Internet 